\title{
Linear Multi-Target IPF Algorithm for Automatic Tracking
}

\author{
Zvonko Radosavljević ${ }^{1)}$ \\ Taek Lyul Song ${ }^{2)}$ \\ Branko Kovačević ${ }^{3)}$
}

\begin{abstract}
The radar tracking applications perform single and multiple object detections from noise-corrupted signal. These detections are used as measurements for target tracking. Tracking in cluttered environments requires false track discrimination and data association. However, data association for tracking closely located multiple targets in heavy clutter is prohibitive due to the excessive computational requirement. This results from exponential growth of mutually exclusive and exhaustive feasible joint events for track-to-measurement assignment. Specifically, our approach treats possible detections of targets followed by other tracks as additional clutter measurements. It starts by approximating the a priori probabilities of measurement origin. These probabilities are then used to modify the clutter spatial density at the location of the measurements. The probability of target existence is used to discriminate the false tracks. The extended simulations showed the effectiveness of this approach in two different multi-target tracking scenarios.
\end{abstract}

Key words: radar tracking, target designation, target tracking, moving target, automatic target tracking, algorithm.

\section{Introduction}

$\mathrm{E}_{\mathrm{s}}$ $\mathrm{ACH}$ of the sensor measurements may either be a spurious (clutter) or a target measurement. The target existence and trajectory are not a priori known. Target measurements are only present in a scan with some probability of detection $P_{D}$. In a multi-target situation, the measurements may have also originated from one of various targets. Targets may enter and leave the surveillance region at any time, thus at any given moment the number of targets in the surveillance area is unknown. Automatic tracking in this environment initiates tracks using both target and clutter measurements [1].

If a track follows a target, we call it a true track; otherwise we call it a false track. To confirm likely tracks and terminate unlikely ones, a track quality measure is necessary [2]. Some standard track quality measures include the probability of target existence. The tracks are initialized using measurements, thus both true tracks and false tracks simultaneously exist. The false track discrimination (FTD) is a procedure to terminate a majority of false tracks and confirm majority of true tracks [3]. A track quality measure needs to be calculated for a successful FTD.

The Multi Hypothesis Tracking (MHT) [3,4] uses the track score (Sequential Probability Ratio Test - SPRT) as a track quality measure. The probability of target existence is first introduced for the single target Integrated Probabilistic Data Association (IPDA) [5], and then for the multi-target Joint IPDA (JIPDA) [6] and Linear Multi-target IPDA (LMIPDA) algorithm $[7,8]$. The IPDA based algorithms approximate the trajectory state probability density function $(p d f)$ by a Gaussian pdf. The single target Integrated Track Splitting
(ITS) [9] and multi-target Joint ITS (JITS) and Linear Multitarget ITS (LMITS) algorithms are the extensions of IPDA, JIPDA and LMIPDA to multi-target environments, respectively. They employ multi-scan data association similar to the $M H T$ so that they are more effective in low detection probability and high clutter measurement density environments. The MHT, IPDA and ITS based algorithms are derived assuming linear trajectory propagation and linear measurement model. Some nonlinearity may be accommodated by the measurement conversion and by replacing the Kalman filter with the Extended Kalman Filter $(E K F)$ or the Unscented Kalman Filter $(U K F)[10,11]$

The particle filters [12] sample the trajectory state $p d f$ by a set of random particles. They accommodate both non-linear measurements and non-linear state propagation. The particle filters have been successfully applied to a wide range of estimation problems. On the negative side, a large number of particles are often needed for difficult multidimensional scenarios, which typically results in about one to two orders of magnitude higher computational requirements compared to Gaussian Mixture ITS $[12,13]$. However, with the technology progress this issue will become less important.

The Integrated Track Splitting (ITS) [14-16] filter is an advanced method for automatic target tracking in a heavy clutter, and the track state includes a track quality measure which is presented with the probability of target existence for the FTD. The Integrated Particle Filters (IPF) [17], [18] track state also includes the target trajectory estimate in the form of a set of mutually exclusive probability density function.

The linear multi-target generalization of IPF, named Linear Multi-Target IPF, is presented in this paper.

\footnotetext{
1) Military Technical Institute (VTI), Ratka Resanovića 1, 11132 Belgrade, SERBIA

2) Hanyang University, Department of Electronic Systems Engineering, Ansan, REPUBLIC OF KOREA

3) University of Belgrade, Faculty of Electrical Engineering, Bulevar kralja Aleksandra 73, Belgrade, SERBIA

Correspondence to: Zvonko Radosavljević; e-mail: zvonkor@verat.net
} 
The paper is organized as follows: after common considerations, a problem statement is presented in Section II. Section III derives the particle filter approach, followed by the recursion of integrated particle filter, linear multitarget data association approach and concluding remarks, presented from Section IV, Section V and Section VI, respectively.

\section{Problem statement}

Tracks are initialized and updated using random measurements of unknown origin, thus each track may be a true track (following a target) or a false track. Target tracking involves determining the existence and the trajectory of possible targets in the surveillance space, by comparing random measurements received by the sensor with the applicable stochastic models. We use superscripts $\tau$ to denote tracks, and also targets followed by tracks; the exact meaning is determined by the context.

\section{Targets model}

In this paper we use the Markov Chain One model [5] for the propagation of the probability of target existence $(\psi)$. This model assumes that a target may exist and when it does it is always detectable with a given probability of detection $P_{D}$, or it may not exist. During the targets maneuvering, the motion can be changed at random times. The trajectory of a target can be described at any time by one of $\sigma_{k}^{\tau}$ predefined dynamic models. A linear model is considered. The target trajectory state, for the linear system, $x_{k}^{\tau} \in R^{n_{z}}$ at time $k$, evolves by:

$$
x_{k}^{\tau}=F_{k} x_{k-1}^{\tau}+v_{k}^{\tau}
$$

where $F_{k}$ is the propagation matrix, and the process noise $v_{k}^{\tau}$ is a zero mean and white Gaussian sequence with covariance $Q_{k}$. At each scan $k$, the sensor returns a random number of the random target and clutter measurements. The measurement of the existing and detectable target is taken with a probability of detection.

\section{Sensors model}

At each scan the sensor returns a random number of the random target measurements and a random number of the random clutter measurements. The measurement of the existing and detectable target is taken with a probability of detection $P_{D}$.

$$
y_{k}^{\tau}=H x_{k}^{\tau}+w_{k}^{\tau}
$$

where $H$ is measurements matrix and the measurements noise $w_{k}^{\tau}$ is zero mean and white Gaussian sequence with covariance matrix $\mathrm{R}$.

\section{Measurements model}

Measurements may originate from the targets as well as from other objects. The clutter measurements follow the Poisson distribution. We assume that the uniform intensity of the Poisson process at point $y$ in the measurement space, termed here the clutter measurement density and denote by $\rho(y)$ is a priori known, or can be estimated using the sensor measurements. At time $k$, one sensor delivers a set of measurements denoted by $z_{k}=\left\{z_{k, j}\right\}_{j=1}^{M_{k}}$. The measurement set may be empty with $M_{k}=0$. Denote by $Z^{k}$ the sequence of selected measurement sets up to including time $k$, $Z^{k}=\left\{Z^{k-1}, z_{k, 1}, \ldots, z_{k, j}, \ldots, z_{k, M_{k}}\right\}$.

\section{Particle Filter Approach}

Particle filtering samples a continuous posterior density function of interest into a set of the weighted particles. If the weights are chosen appropriately, then these weighted set of particles represents the posterior density in a way that the posterior density function can be represented arbitrarily close to the equivalent set of the weighted particles. The target trajectory state $p d f$ at scan $k$ is defined by a set of particles $\left\{x_{k}, w_{k}\right\}$, parameterized by a set of $N$ particles

Particles:

$$
\left\{w_{k}^{i}, x_{k}^{i}\right\}_{i=1}^{N}
$$

where should be satisfied:

$$
\sum_{i=1}^{N} w_{k}^{i}=1
$$

\section{Integrated Particle Filter recursion}

The tracks state consists of the targets existence event, and the trajectories state, and for each track we recursively calculate the probability of target existence, and the trajectory state $p d f$, which is only defined conditioned on the target existence. Depending on the calculated probability of the target existence, we may conclude that the target exists and confirm the track. Each confirmed track stays confirmed until the termination.

Each track is represented by a set of particles. A new $p d f$ is formed by each pair of particle-measurements. For track, each particle for the track propagates according to (1). One cycle of the Integrated Particle Filter algorithm consists of five steps: track propagation, measurements selection, data association, particle weight update and resampling.

\section{Track propagation:}

Each track is a set of particles. The estimation state of each particle is the output of a filter which is given a single measurement at each scan. Propagation does not change relative particle weight. The probability of the target existence is given by:

$$
\hat{\psi}_{k-1}^{\tau}=p_{11} \psi_{k-1}^{\tau}
$$

where $p_{11}$ is a transition probability. During the overall recursion, the number of particles is kept constant. At this time, each of the particles $i$, from the $k-1$ scan, propagates as a Kalman Filter prediction step. The linear propagation model is a special case, given by the:

$$
x_{k}^{\tau, i}=F_{k} x_{k-1}^{\tau, i}+v_{k}^{\tau, i}
$$

where the additive plant noise $v_{k}^{\tau, i}$ is a zero mean Gaussian sequence with covariance matrix $Q_{k}^{\tau, i}, i=1,2, \ldots, N_{k-1}$.

\section{Measurements Selection and Likelihood}

After the prediction step, a two-tier measurements selection 
procedure is performed. The purpose of the measurement selection is to decrease the computational requirements by reducing the number of measurements used to update track $\tau$. For each measurement $z_{k, j}$ and each particle $i$ we calculate innovations $\vartheta_{i, j}$ as follows:

$$
\vartheta_{i, j}=z_{k, j}-H x_{k}^{\tau, i}
$$

and the likelihood of the measurement $z_{k, j}$ with respect to the particle $i$ is:

$$
p_{k, j}^{i}=\left[\frac{1}{\sqrt{2 \pi|R|}}\right] \exp \left(-0.5 \cdot \vartheta_{i, j}^{\tau}{ }^{T} R^{-1} \vartheta_{i, j}^{\tau}\right)
$$

where $(\cdot)^{T}$ denotes the matrix transpose. The likelihood of the measurement $z_{k, j}$ is:

$$
p_{k, j}^{\tau}=\sum_{i} w_{k-1}^{\tau, i} p_{k, j}^{\tau, i}
$$

\section{Data association}

Each track $\tau$ selects a set $z_{k}$ of $M_{k}$ candidate measurements, the probability the target measurement is calculated by using the measurement likelihood ratio defined by:

$$
\lambda_{k}^{\tau}=1-P_{D}+P_{D} \sum_{j=1}^{M_{k}} \frac{p_{k, j}^{\tau}}{\rho_{k, j}}
$$

Then, the particle weight that represents the updated target trajectory state pdf is updated by using the data association probabilities $\beta_{k, j}^{\tau}$, for each track $\tau$, such as target trajectory update:

$$
w_{k}^{\tau, i}=w_{k-1}^{\tau, i}\left(\beta_{k, 0}^{\tau}+\sum_{j=1}^{M_{k}} \beta_{k, j}^{\tau} \frac{p_{k, j}^{\tau, i}}{p_{k, j}^{\tau}}\right)
$$

where $\beta_{k, j}^{\tau}$ represents the posterior probability that the $j^{\text {th }}$ measurement at scan $k$ is the true target measurement and where $\beta_{k, 0}^{\tau}$ represents the probability that none of the selected measurements is target originated. The probability of the target existence is updated by the equation:

$$
\psi_{k}^{\tau}=\frac{\lambda_{k}^{\tau} \hat{\psi}_{k-1}^{\tau}}{1-\left(1-\lambda_{k}^{\tau}\right) \hat{\psi}_{k-1}^{\tau}}
$$

\section{Particle Weight Update}

Next step is the target trajectory update, by the particles weight update:

$$
w_{k}^{\tau, i}=w_{k-1}^{\tau, i}\left(1-P_{D}+P_{D} \sum_{j=1}^{M_{k}} \frac{p_{k, j}^{\tau, i}}{\rho_{k, j}^{\tau}}\right)
$$

\section{Resampling}

Particle filter recursions tend to increase the variance of sample weights $\left\{w_{k}^{i}\right\}$, where only a small number of particles have significant weight. This is known as a sample degeneracy and can lead to the particle filter divergence. Resampling corrects this problem [8] by removing the particles with small weights, and multiplying the particles with high weight. After resampling, all surviving particles have identical weight $w_{k}^{i}=1 / N$.

There are multiple possible ways to detect the need for resampling, as well as to perform resampling. The resampling details and tradeoffs are beyond the scope of this paper, useful discussions and tradeoffs may be found in $[11,12]$ and the references within.

\section{Linear Multi-target Integrated Particle Filter Data Association}

Linear multi-target (LM) is a suboptimal multi-target tracking technique which reduces complexity by eliminating joint measurements to tracks assignments. It also significantly reduces algorithmic complexity. LM derivations are presented in [18], thus here we only present the final formulae. When updating track $\tau$ possible detections of targets being followed by other tracks are unwanted measurements. The LM method modulates the clutter measurement density $\rho_{k, i}$ of each selected measurement $z_{k, i}$ of track $\tau$ by a possible contribution of other tracks. Target state is then updated using a single target tracking filter.

The a priori probability that the $i^{\text {th }}$ measurement is originated by the $j^{\text {th }}$ target is given by:

$$
p_{k, j}^{\tau}=\tilde{\psi}_{k-1}^{\tau} \frac{\tilde{p}_{k, j}^{\tau} / \rho_{k, j}}{\sum_{l=1}^{M_{k}} p_{k . l}^{\tau} / \rho_{k . l}}
$$

The modified clutter density for track $\tau$ at measurement $z_{k, j}$ is:

$$
\Theta_{k, j}^{\tau}=\rho_{k, j}+\sum_{\theta=1 ;(\theta \neq \tau)}^{\tau_{T}} \frac{p_{k, j}^{\theta}}{1-p_{k, j}^{\theta}}
$$

where $\tau_{T}$ is the total number of tracks. To calculate data association probabilities for target $\tau$, single-target IPF formulae are used with $\Theta_{k, j}^{\tau}$ replacing $\rho_{k, j}$. If the targets are far apart $\Theta_{k, j}^{\tau}=\rho_{k, j}$ for all $i$ and $j, L M I P F$ becomes identical to $I P F$. Measurement likelihood ratio for track $\tau$ at time $k$ is given by the following equation:

$$
\lambda_{k}^{\tau}=1-\tilde{P}_{D}+\sum_{j=1}^{M_{k}} \frac{\tilde{p}_{k, j}^{\tau}}{\Theta_{k, j}^{\tau}}
$$

A posteriori state estimate of the measurement $\mathrm{j}$ is given by:

$$
\beta_{k, j}^{\tau}=\frac{1}{\lambda_{k}^{\tau}}\left\{\begin{array}{l}
1-\tilde{P}_{D}, \quad i=0 \\
\tilde{P}_{D} \frac{p_{k, j}^{\tau}}{\rho_{k, j}}, i \geq 0 .
\end{array}\right.
$$

Then, a posteriori probability of the target existence is given by (12).

\section{Results of simulations}

The application selected for the study was a two dimensional (positions and velocities), four-state aircraft tracking problem in which the sensor observes both position coordinates. The area under surveillance was $x=[0 ; 1000][\mathrm{m}]$ long and $y=[0 ; 1000][\mathrm{m}]$ wide. Simulations have been 
performed by choosing $N_{k}=N=1000$ particles.

In the initialization process, creating a total of $N_{k}$ particles on the track, schedules are: position have Gaussian distribution, and the speeds have uniform distribution in a circle with the center at zero and radius $v_{\max }$. Both dimensions were assumed independent. The transition probability for the Markov Chain One model are chosen by the $p_{11}=0.98$.

The IPF parameters are calculated on-line according to the appropriate equations. Period of scanning is $T=1 \mathrm{~s}$. All experiments were conducted on the basis of multi target tracking $(M T T)$ for two and fifteen targets scenario. Transition matrix and process noise matrix are given by:

$$
\begin{gathered}
F=\left[\begin{array}{llll}
1 & T & 0 & 0 \\
0 & 1 & 0 & 0 \\
0 & 0 & 1 & T \\
0 & 0 & 0 & 1
\end{array}\right] \\
Q=q\left[\begin{array}{cccc}
T^{2} / 4 & T^{3} / 2 & 0 & 0 \\
T^{3} / 2 & T & 0 & 0 \\
0 & 0 & T^{4} / 4 & T^{3} / 2 \\
0 & 0 & T^{3} / 2 & T
\end{array}\right]
\end{gathered}
$$

and measurements matrix are given by

$$
H=\left[\begin{array}{llll}
1 & 0 & 0 & 0 \\
0 & 0 & 1 & 0
\end{array}\right]
$$

The measurements noise vector are independent Gaussian noise with constant covariance matrix, given by the

$$
R=\left[\begin{array}{cc}
\sigma_{x}^{2} & 0 \\
0 & \sigma_{y}^{2}
\end{array}\right]
$$

where $\sigma_{x}^{2}=\sigma_{y}^{2}=25\left[\mathrm{~m}^{2}\right]$

The selected scenarios were presented for the first time in literature [11]. Two sets of simulation experiments are presented in this section: the two targets (Fig.1.) and fifteen targets (Fig.2.) simulation experiments. Both experiments consist of 500 Monte Carlo runs. Each run lasted for 40 scans. The intention is to show the improvements in multi-target situations that can be obtained by using standard IPF and ITS against LMIPF and LMITS procedure

Instead of the recent IPF single target tracking experiments [35], a MTT scenario will be presented. Targets are initially positioned at the edges of a circle with the centre at $(500,500)$ and a radius of 450, for the both, two and fifteen targets experiments. Each target moves with a uniform speed towards the centre of the circle, which they should reach in 20 scans, after which they carry on with the uniform motion for further 20 scans. A random component is added to the speed vector of each target, thus at scan 20 the variance of the distance between each target and the centre of the circle will be double the sensor measurement error noise covariance matrix. In the two targets scenario, the targets initial separation is $20^{\circ}$, instead of fifteen targets scenario with the targets initial separation $10^{\circ}$. The following definitions of true and false tracks are used.

1. Each initiated track is false with respect to all existing targets.
2. A false track becomes a true track with respect to a target when the state estimate is sufficiently close to the true target state.

3. A track that is true with respect to a target will remain true for as long as it selects the target detections

Each simulation experiment consists of a number of simulation runs. In each simulation run, targets will repeat their trajectories. The measurements are generated independently. Each algorithm uses the same set of measurements. False tracks may be initiated using target measurements, either in a conjunction with a clutter measurement, or by using measurements from different targets in different scans.

Thus, the average number of initialized false tracks per scan will depend on the number of targets present. The average number of initialized false tracks per scan was 8 , and 120 for the two and fifteen targets experiments, respectively.

A confirmed false track in one scan is 300 and 200 for the two and fifteen targets cases, respectively. The performance measures used to compare the algorithms confirmed true tracks, root mean square error positions and target retention statistics. Results are presented by a number of confirmed true tracks and Root Mean Square Error Position.

The target retention statistics was obtained by noting the identity of the confirmed true track following each of the targets at scan 14 . These identities are checked again at scan 38 , and the following statistics is accumulated for each experiment:

nCases: total number of cases of a target being followed by a confirmed track at scan 14 ;

nOK: percentage of tracks still following the original target at scan 38 ;

nSwitched: percentage of tracks that end up following a different target at scan 38;

nLost: percentage of tracks not following any target at scan 38,

nMerged: percentage of tracks lost due to merging between tracks counted in nCases between scans 14 and 38

\section{Two targets simulations}

Simulation scenario with two targets is presented in Fig.1 Confirmed true tracks diagram and root mean square diagram are presented in Fig.2 and in Fig.3, respectively.

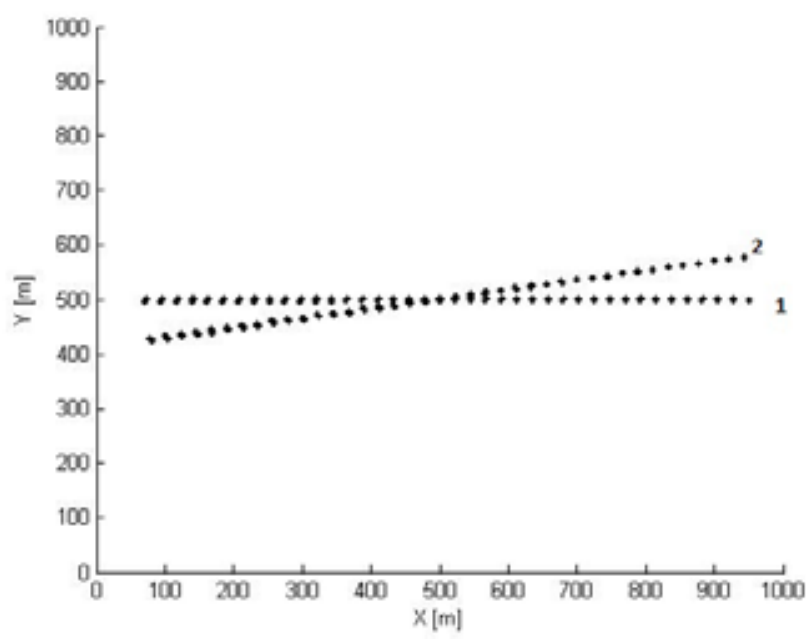

Figure 1. Two targets scenario 


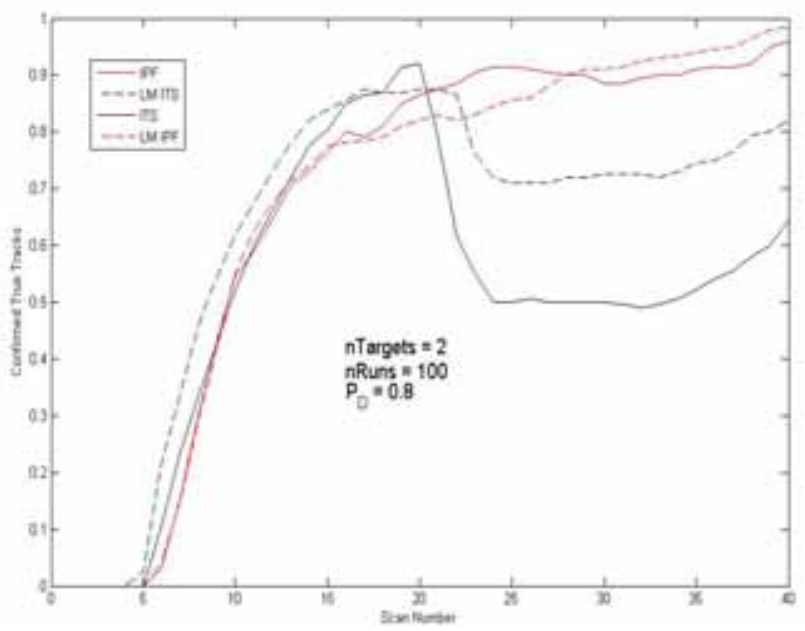

Figure 2. Number of confirmed true tracks (two targets)

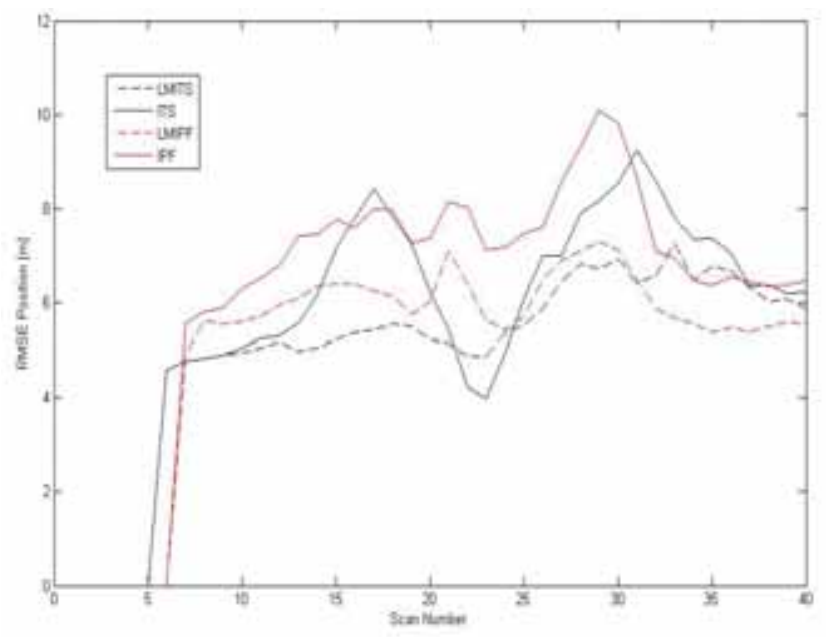

Figure 3. RMS error over time (two targets scenario)

\section{Fifteen targets simulations}

Simulation scenario (fifteen targets) is presented in Fig.4. Confirmed true tracks diagram and root mean square diagram are presented in Fig.5. and in Fig.6., respectively.

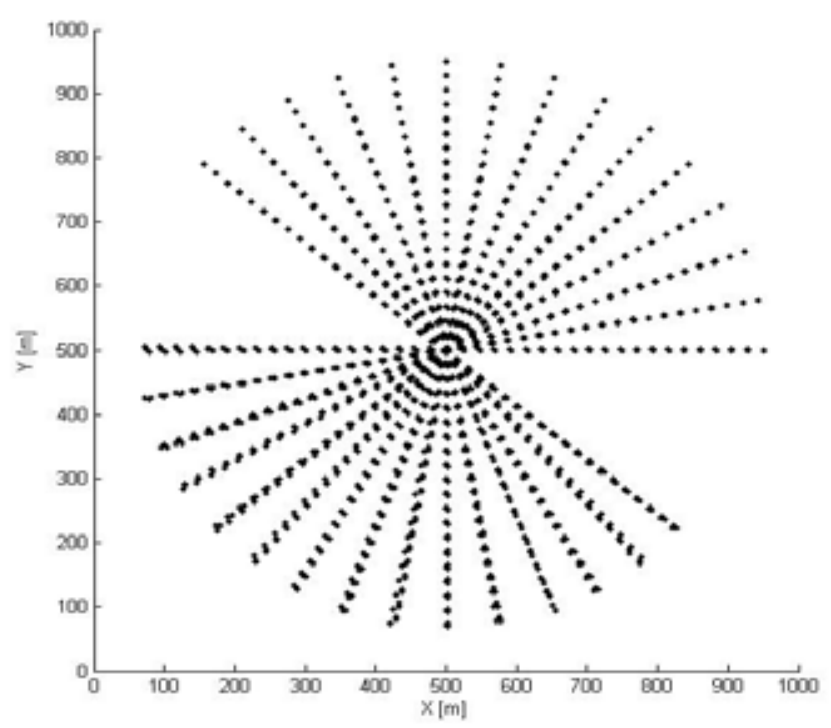

Figure 4. Fifteen targets scenario

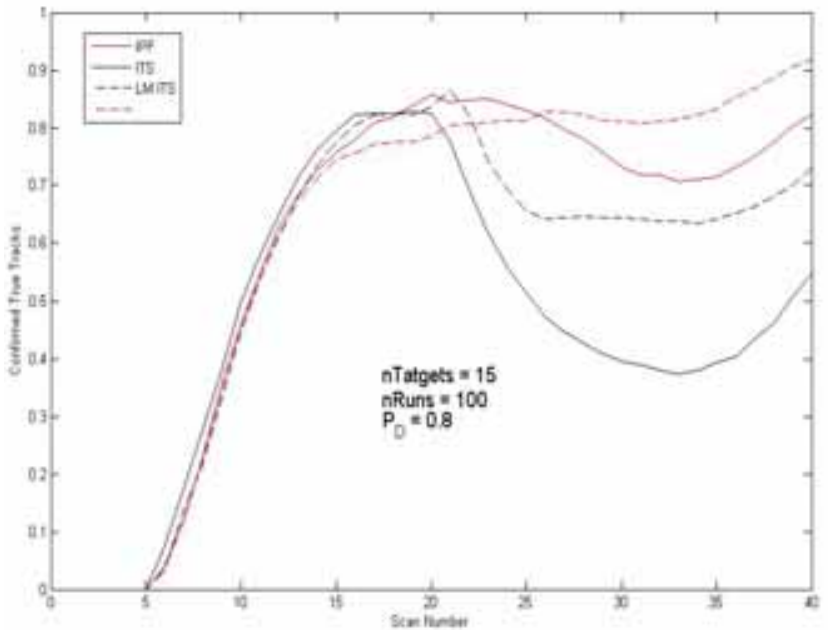

Figure 5. Number of confirmed true tracks (fifteen targets scenario)

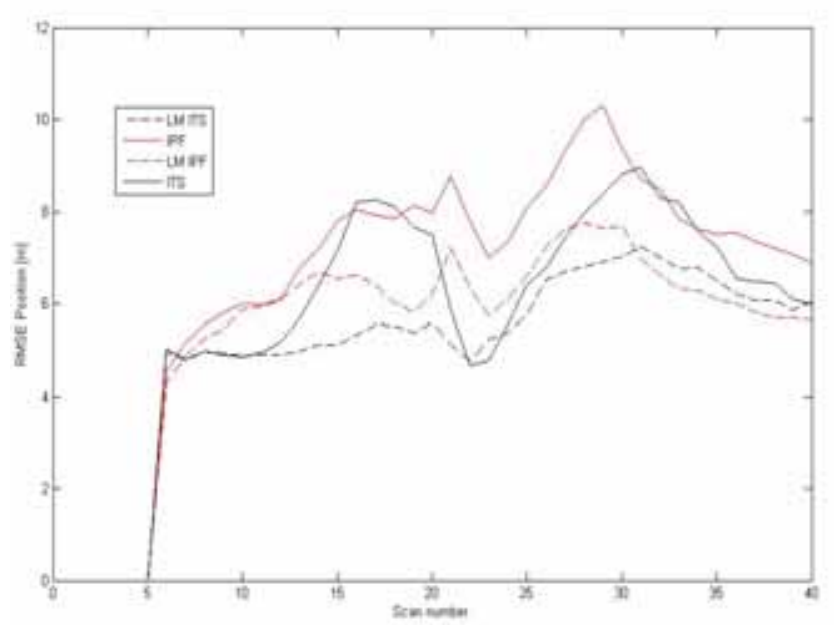

Figure 6. RMS error over time (fifteen targets scenario)

Table 1. Target Retention-Two Targets

\begin{tabular}{|c|c|c|c|c||}
\hline & ITS & LMITS & IPF & LMIPF \\
\hline \hline$n$ Cases $[\mathrm{n}]$ & 148 & 148 & 144 & 152 \\
\hline$n$ OK $[\%]$ & 79.7 & 100 & 97.9 & 100 \\
\hline$n$ Switched $[\%]$ & 1.4 & 0 & 0 & 0 \\
\hline nLost $[\%]$ & 18.9 & 0 & 2.1 & 0 \\
\hline Merged $[\%]$ & 21 & 0 & 0 & 0 \\
\hline
\end{tabular}

Table 2. Target Retention-Fifteen Targets

\begin{tabular}{|c|c|c|c|c||}
\hline & ITS & LMITS & IPF & LMIPF \\
\hline \hline$n$ Cases $[\mathrm{n}]$ & 1165 & 274 & 282 & 274 \\
\hline$n$ OK $[\%]$ & 23.7 & 76.6 & 61 & 76.6 \\
\hline$n$ Switched $[\%]$ & 17.9 & 15.4 & 13.8 & 15.3 \\
\hline$n$ Lost $[\%]$ & 58.4 & 8 & 25.2 & 8.1 \\
\hline Merged $[\%]$ & 527 & 7 & 33 & 7 \\
\hline
\end{tabular}

Results of the Integrated Particle Filter-multiple targets (two and fifteen targets) tracking simulations showed better confirmed true tracks and target retention statistics than the standard ITS algorithm that was recently presented. At the same time, linear multi targets methodology (LMITS and LMIPF) shows better statistics results than the standard ITS and IPF algorithms.

Especially, the increase of the number of targets and decrease the targets initial separation show better targets statistics in favour of IPF. 


\section{Conclusion}

The multiple target tracking algorithm, generalizations of standard IPF, named Linear Multi-target IPF, is proposed and was tested in a special scenarios with a small (two) and large (fifteen) number of crossing targets. It uses the well-known features of ITS algorithms that account the probability of target existence of objective forms, trace and ease of use offered by the Particle Filter. Results of two and fifteen targets simulations showed better confirmed true tracks and target retention statistics than the standard ITS algorithm, with the CPU loss time. In the next step of the research it is necessary to examine the possibility of improving computational efficiency by choosing significant and discrimination weakness particle weights.

In this sense it is necessary to study the limits of target existence in the heavy clutter environments, increasing the number of particles.

\section{References}

[1] SINGER,R.: Estimate Optimal Tracking Filter Performance for Manned Maneuvering Targets, IEEE Trans. Aerospace and Electronic Systems, July 1970, Vol.6, No.4, pp.473-483.

[2] BLACKMAN,S., POPOLI,R.: Design and Analysis of Modern Tracking Systems, Artech House, 1999.

[3] BLACKMAN,S.: Multiple-target tracking with radar applications, Artech House, 1986.

[4] REID,D.B.: An Algorithm for Tracking Multiple Targets, IEEE Transactions on Automatic Control, December 1979, Val AC-24, pp.843-854,

[5] MUŠICKI,D., EVANS,R. STANKOVIĆ,S.: Integrated Probabilistic Data Association (IPDA), IEEE Trans, Automatic Control, Jun 1994, Vol.39, No.6, pp.1237-1241.

[6] HUE,C.C., LE CADRE,J.P., PEREZ,P.: Sequential monte carlo methods for multiple target tracking and data fusion, IEEE Trans. Signal Processing, February 2002, Vol.50, No.2, pp.309-325.
[7] VERMAAK,J., GODSILL,J., SIMON,J., PEREZ,P.: Monte carlo filtering for multi-target tracking and data association, IEEE Trans. Aerospace Electronic Systems, January 2005, Vol.41, No.1, pp.309332.

[8] BAR-SHALOM,Y., TSE,E.: Tracking in a cluttered environment with Probabilistic Data Association, Automatica, September 1975, Vol.11, pp.451-460.

[9] MUŠICKI,D., LA SCALA, B., EVANS,R.: The Integrated Track Splitting filter-efficient multi-scan single target tracking in clutter, IEEE Trans. Aerospace Electronic Systems, October 2007, Vol.43, No.4, pp.1409-1425.

[10] MORELANDE,M., CHALLA,C.: Maneuvering target tracking in clutter using Particle Filters, IEEE Trans. Aerospace Electronic Systems, January 2005, Vol.41, No.1, pp.252-270.

[11] MORELANDE,M.R., MUŠICKI,D.:, Fast multiple target tracking using particle filters, in 44th IEEE Conference on Decision and Control, CDC 2005, Seville, Spain, December 2005, pp.530-535.

[12] MARRS,A., MASKELL,S., BAR-SHALOM,Y.: Expected Likelihood for Tracking in Clutter with Particle Filters, SPIE, Vol.4728, Signal and Data Processing of Small Targets 2002, Orlando, April 1-5, 2002.

[13] D. Mušicki D.: Bearings only multi-sensor maneuvering target tracking, Systems Control Letters, March 2008, Vol.57, No.3, pp. 216221.

[14] RISTIC,B., ARULAMPALM,S., GORDON,NJ.: Beyond the Kalman Filter: Particle Filters for Tracking Applications, Artech House, 2004.

[15] MUŠICKI,D., EVANS,R.: Integrated probabilistic data association finite resolution, Automatica, April 1995, Vol.31, pp.559-570.

[16] SONG,T.L., MUŠICKI,D., KIM,D.S.: Target Tracking with Target State Dependent Detection, IEEE Transactions on Signal Processing, March 2011, Vol. 59, No.3, pp.1063-1074.

[17] RADOSAVLJEVIĆ,Z., MUŠICKI,D., KOVAČEVIĆ,B., KIM,W.C., SONG,T.L.: Integrated particle filter for target tracking, IET proceedings on Radar Sonar and Navigation, May 2015.

[18] RADOSAVLJEVIĆ,Z., MUŠICKI,D., KOVAČEVIĆ,B., KIM,W.C., SONG,T.L.: Integrated particle filter for target tracking, Proc. in 13th International Conference on Electronics, Information and Communication, ICEIC 2014, Kota Kinabalu, Malaysia, January 2014.

Received:22.01.2016. Accepted:25.03.2016.

\title{
Algoritam linearnog sjedinjavanja čestica više tragova za automatsko praćenje ciljeva
}

\begin{abstract}
Postupak radarskog praćenja podrazumeva detekciju jednog ili više ciljeva iz signala u okruženju šuma. Detekcije se koriste kao merenja za praćenje ciljeva. Praćenje u okruženju klatera zahteva odbacivanje lažnih tragova i pridruživanje podataka. U radu je predložena linearna generalizacija praćenja ciljeva koja na lak način omogućava premošćavanje ovog koraka i u potpunosti korišćenjem asocijativnih verovatnoća i rekurzivno proračunava verovatnoću postojanja traga.

Na poseban način, predloženi pristup tretira moguće detekcije ciljeva koji potiču od drugih ciljeva kao dodatna klater merenja. On počinje aproksimacijom apriorne verovatnoće porekla merenja sa radarskog senzora. Ove verovatnoće se zatim koriste za modifikovanje prostorne gustine klatera na lokaciji merenja.

Verovatnoće postojanja cilja mogu da se koriste za odbacivanje lažnih tragova. Algoritam podrazumeva model propagacije trajektorije više ciljeva i zavisnost verovatnoće postojanja cilja od stanja cilja. Sprovodeći intenzivne simulacije sa dva različita scenarija kretanja više ciljeva, pokazana je efikasnost predložene generalizacije.
\end{abstract}

\section{Линейное обобщение алгоритма объединения частиц следов для автоматического многоцелевого отслеживания}

\footnotetext{
Процесс отслеживания целей радаром включает в себя мониторинг радиолокационного обнаружения одной или нескольких целей из окружающих шумовых сигналов. Обнаружения используются в качестве измерений для мониторинга целей. Мониторинг окружающей клаттерной среды требует отказа ложных ключей (следов) и объединения данных. В данной работе предлагается линейное обобщение мониторинга целей, что позволяет легко обойти этот шаг и полностью с использованием ассоциативных вероятностей рекурсивно вычисляет вероятность существования следа.
} 
Особым образом, предложенный подход трактует может ли обнаруживать цели, которые вытекают из других целей таких как дополнительные измерения местных помех. Он начинает аппроксимируя априорные вероятности происхождения из измерений с радиолокационными датчиками. Эти вероятности затем используются для изменения пространственной плотности местных помех на месте измерения.

Существование объективной вероятности целей может быть использовано, чтобы отвергнуть ложные следы. Алгоритм включает в себя модель распространения траекторий больше целей и зависимость вероятности существования цели от состояния цели. Проводя интенсивные моделирования с двумя различными сценариями движения больше целей, здесь продемонстрирована эффективность предлагаемого обобщения.

Ключевые слова: отслеживания целей радаром, обнаружения целей, сопровождения целей, движущаяся цель, автоматические сопровождения целей, алгоритм.

\title{
La généralisation linéaire de l'algorithme de l'association des particules de piste pour le suivi automatique de plusieurs cibles
}

\begin{abstract}
Le procédé du suivi par le radar comprend la détection d'une ou plusieurs cibles à partir du signal dans l'environnement de bruit. Les détections sont utilisées comme les mesurages pour le suivi des cibles . Le suivi dans l'environnement de désordre demande l'élimination de fausses pistes et l'association des données. Dans ce travail on propose la généralisation linéaire de suivi des cibles qui permet facilement de franchir ce pas entièrement en employant les probabilités associatives et elle calcule récursivement la probabilité de l'existence des pistes. $L$ 'approche proposée traite particulièrement les détections possibles des cibles qui proviennent des autres cibles comme le mesurage additionnel de désordre. Cela commence par l'approximation de la probabilité à priori de l'origine de mesurage depuis le capteur de radar. Ces probabilités sont ensuite utilisées pour la modification de la densité spatiale de désordre à l'endroit de mesurage. Les probabilité de l'existence de cible peuvent s'appliquer pour éliminer les fausses pistes. $L$ 'algorithme comprend le modèle de la propagation de trajectoire pour plusieurs cibles et la dépendance de probabilité de l'existence de cible de l'état de cible. En faisant les simulations intenses selon deux différents scénarios du mouvement de plusieurs cibles on a démontré l'efficacité de la généralisation proposée.
\end{abstract}

Mots clés: suivi par radar, détection de cible, suivi de cible, cible mobile, suivi automatique de cible, algorithme. 